\title{
CULTURA DA PAZ E MUNDO VIOLENTO; VERBO E AUSÊNCIA EM PALAVRAS E IMAGENS
}

\section{CULTURE OF PEACE AND VIOLENT WORLD; VERB AND ABSENCE IN WORDS AND IMAGES}

\author{
Marcos Kruse ${ }^{*}$
}

\begin{abstract}
RESUMO
Estabelecer, criar e manter cultura de paz é um processo demorado porque a paz da qual se fala não é um momento e sim, uma condição a que se almeja chegar enquanto sociedade. Cultura de paz significa estabelecer a paz como derivação cultural. Em assim sendo, cultura de paz não é o ponto de partida e sim, o alvo a alcançar. Trata-se, então, de construto a posteriori. Como elemento a priori vem a necessária discussão sobre a ética como fundamento cultural da paz. Isto é assim porque a ética faz as indagações necessárias sobre as condições em que se estabelece cultura de paz. Em qualquer hipótese, a tarefa de construir cultura de paz traz implicações profundas para gerar uma nova interface social dialógica. Não se faz cultura de paz em ambiente de manifesta violência, especialmente quando se considera o aspecto linguístico e simbólico. Violência simbólica e verbal existem antes de haver manifestação como força bruta. Por fim, apesar de enormes dificuldades de construção, entende o autor que fora do estabelecimento e permeio cultural da paz, não resta outra alternativa para a humanidade.
\end{abstract}

Palavras-chave: Processo. Construção a posteriori. Ética da paz. Cultura. Violência simbólica.

\begin{abstract}
Establishing, creating and maintaining a culture of peace is a long process because the peace is not a moment but a condition of being which the society aspire. The culture of peace means establishing peace as a cultural derivation. In that sense, the culture of peace is not the starting point, but the target. It is, then, a construct a posteriori. As an a priori element comes the necessary discussion on ethics as the cultural foundation of peace. This is because ethics makes correct inquiries about the conditions in which a culture of peace is established. In any case, the task of building a culture of peace has profound implications for generating a new dialogical social interface. There is no culture of peace in an atmosphere of overt violence, especially when considering its linguistic and symbolic aspect. Symbolic and verbal violence exist before manifestation as brute force. Finally, despite enormous construction difficulties, the author understands that outside the establishment and cultural permeation of peace, there is no other alternative for humanity.
\end{abstract}

Keywords: Process. Post-construction. Peace ethics. Culture. Symbolic violence.

\footnotetext{
“Teólogo, Economista, Bacharel em Direito e Doutorando em Direito pela UNLZ (Argentina, tese sobre usura).
} 


\section{INTRODUÇÃO}

Sinalagma importante a merecer espaço de reflexão introdutória para o tempo presente é saber que Luiz Inácio Lula da Silva foi indicado, por iniciativa de Adolfo Perez Esquivel, para o Nobel da Paz (HENRIQUE, 2018). Independentemente de qualquer análise que se faça sobre esta indicação, ${ }^{1}$ a própria existência de um prêmio Nobel da Paz é motivo ensejador de renovado interesse reflexivo, dado que se trata, a premiação, não apenas de contribuir para a paz no mundo como, de fato, estabelecer a paz como processo cultural. Ademais, o Brasil jamais recebeu tal honraria, razão pela qual, a indicação de Lula, atualmente em cárcere a exemplo do que ocorreu com Nelson Mandela, se faz pelos notáveis progressos alcançados no tempo de sua presidência para com substancial superação do impostergável problema da fome no Brasil. Além da natural indagação pelos motivos do cárcere, assalta a consciência os motivos de existir proliferação de ódio desmedido e irracional contra a figura do ex-presidente.

Esta proliferação de ódio aponta para a questão da paz não ser apenas a chegada a este ponto numa situação pós-conflito, como de fato fica evidente que a paz se refere como processo que se realiza para evitar ou superar que conflitos cheguem a se manifestar belicamente. Quer dizer, é preciso estabelecer esforços para que a paz se coloque como alvo a alcançar em função de um processo concatenado de iniciativas pertinentes. A paz aí, neste sentido é entendida como um movimento dialógico que recusa o uso da força porque esta, na medida de seu uso, é fator impeditivo do próprio diálogo. Quem bate e está na fase de puxar o gatilho, ou, quem extravasa simbolicamente o ódio, já não precisa e já nem consegue conversar. Então, estamos falando, precisamente, do estabelecimento de um processo cultural em que a paz seja entendida como movimento, como conjunto de ações que a sustentam e a viabilizem rumo à concordância humana.

\footnotetext{
${ }^{1}$ Particularmente, entendo que há bons motivos para o pleito. Curiosamente, em 1936, o prêmio Nobel da Paz foi concedido a Carl von Ossietzky, um jornalista alemão ativista do pacifismo. Na editoria do Weltbühne, criticou a escalada militarista da Alemanha e foi, por isso, acusado de traição e condenado em 1931. Com Hitler na chancelaria, não se amedrontou e criticou duramente o extremismo político, situação que lhe custou nova prisão no ano de 1933. Em 1936 foi transferido para uma prisão hospital e, em tal condição, foi-lhe concedido o Nobel da Paz que não pode receber por estar detido. Hitler, como retaliação, resolveu decretar proibição a que qualquer alemão aceitasse o prêmio Nobel.
}

Por isso mesmo, é preciso saber do que se está a tratar quando se fala em cultura da paz.

É este o tema que nos move à reflexão e isto sob quatro conceitos básicos. O primeiro é que a cultura da paz somente pode ser compreendida como construto $a$ posteriori. Paradoxalmente, somente depois do caminho andado e trilhado é que se pode estabelecer o caminho a percorrer. O segundo conceito importante diz respeito ao estabelecimento da necessária mediação ética em torno da paz. Isto porque, a paz, também ela, tem lado a partir do qual assume sentido ético. Num terceiro olhar abre-se a questão do universo dialógico e linguístico como um dos notáveis fatores que está presente em qualquer esforço cultural. A cultura reproduz dialogicamente a paz que se pretende alcançar. Por fim, e em decorrência da necessária compreensão dialógica, é possível ver que o Brasil de hoje apresenta muitas dificuldades para estabelecer uma cultura de paz. Estas dificuldades são manifestas fortemente no linguajar violento e no mundo simbólico de intolerância generalizada. A cultura de paz se dá, por isso mesmo, como luta em meio a fortes dificuldades compreensivas e dialógicas.

\section{CULTURA DA PAZ COMO CONSTRUTO A POSTERIORI}

É equivocado pensar que haja lições a priori sobre a cultura da paz. Esta se faz a posteriori porque se reconhece, depois, que o movimento feito por pessoas ou instituições se orientou para produzir efeitos sobre a paz enquanto práxis da civilidade. Neste sentido, há pessoas e instituições que servem de paradigma para a consolidação de um conceito de cultura da paz. Nelson Mandela, por exemplo, em sua incansável luta pelo fim do apartheid na África do Sul recebeu, junto com Frederik Willem de Klerk, o prêmio Nobel da paz em 1993. Mas, jamais recebeu a honraria Mahatma Gandhi, este sim, inconteste figura merecedora da honraria. Foi indicado cinco vezes para premiação entre os anos de 1937 a 1948 . Quem sabe a $2^{\text {a }}$ Grande Guerra tenha impedido que o comitê do prêmio tivesse os olhos suficientemente atentos para a figura de Gandhi.

Para o entendimento do que seja cultura da paz é de bom alvitre olhar a atuação de Gandhi. Por certo que a atuação de Jesus de Nazaré entre tantos outros, 
também poderia ser considerada. Mas, fixemo-nos nos exemplos modernos.

Mahatma Gandhi é paradigma porque o contexto em que articulou a sua luta pela paz se deu em meio à violência institucionalizada. Esta violência se caracterizou especialmente pela dominação britânica, notadamente sobre a África do Sul em que o componente racial se fazia presente (FISHER, 1983). Depois de graduar-se em direito na Inglaterra, foi para a África do Sul. Naquele país não conseguiu fama profissional ou dinheiro. Ao invés disso, conseguiu ter desperta a consciência, de um lado, quanto às questões sociais e de outro, sobre a impossibilidade da resistência armada. Foram as lutas raciais da África do Sul que moldaram a estratégia da resistência pacífica à injustiça, por ele denominada satyagraha proposta pela qual se opta pela desobediência civil sem recurso ao uso da violência.

Desta proclamação da recusa à violência não se pode separar o conteúdo da fé que Gandhi abraçara. Recusar a violência era para Gandhi um ato derivado da fé de que todas as pessoas tinham direito inalienável a viverem em paz. Neste sentido, por aliar em sua fé professada a práxis do cotidiano, Gandhi é figura central no diálogo inter-religioso. (MARCONDES, et al. 2012) O direito de uma pessoa não se sobrepõe ao direito do outra. Esta fé estabelece o paradigma da verdade pelo qual se pautou Gandhi. Quando se ataca o outro, na verdade, $o$ ataque se faz, na mesma proporção, contra o próprio atacante porque identificar-se com o outro é claro sinal da consciência de humanidade. Por tal propósito, lecionou aos que o ouviam, "a força de um homem e de um povo está na não-violência. Experimentem."

Considerando os movimentos de Gandhi, fica claro que ele se mantinha numa permanente postura de recusa ao uso da violência, não apenas da violência enquanto ativa, agressiva, como também distância da violência reativa, aquela que se ampara pelas doutrinas da legítima defesa com a decorrente excludente de ilicitude. Isto vale dizer que Gandhi não reagia com violência em resposta à violência que sofria. Esta postura foi motivo de muita incompreensão e, do ponto de vista da luta revolucionária, uma atitude de todo inexplicável (BAMAN, 2016).

O PCI, Partido Comunista da India chegou a criar uma liga contra o gandhismo porque, a seu ver, a tática da recusa à violência como meio de reação não contribuia para o processo histórico e revolucionário. Sobre tal posicionamento, Gandhi entendia que a revolução a processar-se deveria ser no interior de cada pessoa e não pela luta violenta que acontece em direção ao outro.

Este propósito de atuação também foi decisivo para Martin Luther King nos Estados Unidos. Tal qual Gandhi, Luther King percebeu que a luta violenta geraria reação contrária de muito maior envergadura. A população preta nos Estados Unidos nas decadas de 1960 - 1970 não era população armada. A possibilidade de se conseguir algo pela via violenta não era opção viável a se considerar. O que se coloca em questão por parte dos anarquistas contemporâneos é que a falta de reação por meio da recusa à violência acaba por proteger o Estado (GELDERLOOS, 2007).

Também a atuação de Luther King gerou reações de indignação e protesto, seja de parte da SNCC (Student Nonviolent Coordinating Committee) $)^{2}$ quanto, de modo mais incisivo, da parte de Malcom X. Luther King e Malcom X lutavam pela mesma causa. Mas, a luta se processava sob diferentes abordagens. Malcom defendia o enfrentamento como forma de superação dos problemas de discriminação racial. A violência, para Malcolm era um modo de se produzir transformações sociais. Tanto Luther King que defendia a resistência não violenta quanto Malcom que defendia a resistência, inclusive por meio da violência foram assassinados a tiros.

Num ponto de consideração adicional há que falar-se na figura de Bob Marley. Este notável artista jamaicano também toma parte no processo reflexivo porque, apesar de lutar contra as injustiças, defendeu, tal qual os Beatles no final da década de 1960, que tudo o que se necessita é o amor (SPITZ, 2007, pp. 692-698), mensagem transmitida, pela primeira vez worldwide para o programa de TV Our World.

É perfeitamente claro que Bob Marley tinha plena consciência da situação de opressão da população negra e das injustiças presentes no mundo. Mas, perante a disputa nas eleições gerais de 1976 da Jamaica, Bob Marley entendeu que seria importante apresentar-se num show gratuito para a população. Michael Manley primeiro-ministro vinculado do

\footnotetext{
${ }^{2}$ É deste grupamento de jovens que sai a figura de Stokely Carmichael, líder do movimento Black Power e dos Panteras Negras. Com os panteras negras e o movimento Black Power, assumiu em definitivo a posição política socialista e revolucionária.
} 
PNP (People's National Party) de vertente socialista considerou a ideia excelente até porque, poderia ser utilizada politicamente. Entrementes, a oposição ao socialismo jamaicano, que tinha apoio dos Estados Unidos, não gostou do movimento e intentou assassinar Marley. Este, depois de sair do hospital, realizou o show e, posteriormente, num show havido em 22 de abril de 1978 em Kingston, reuniu, num ato que beira ao grotesco pelo contragosto, as figuras de Michael Manley e Edward Seaga do Partido Trabalhista Jamaicano (JLP), de direita no expectro político, num aperto de mão.

Figura 1: Concerto One Love em que Bob Marley junta as mãos de Edward Seaga e Michael Manley

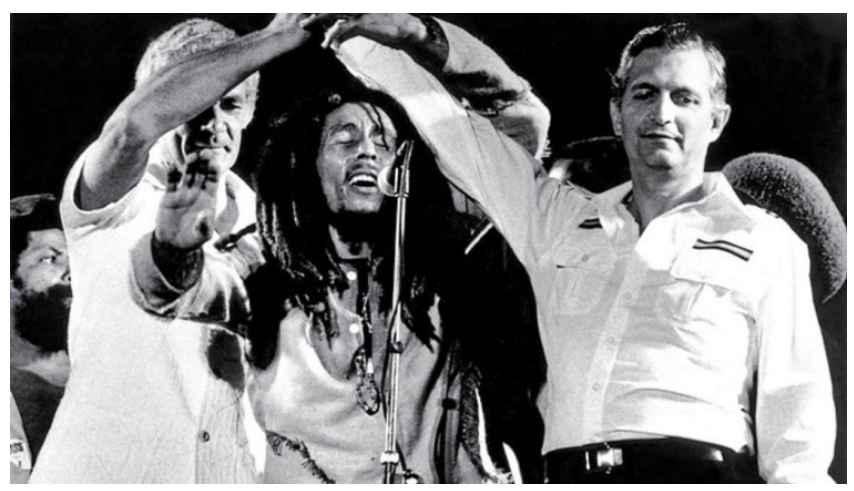

FONTE: https://www.historiadasartes.com/prazer-em-conhecer/ jean-baptiste-debret/ [Internet]

Este encontro das mãos, todavia, acabou por se tornar ícone de uma ideia, de um movimento que não conseguiu realizar-se na prática. $\mathrm{O}$ apelo do concerto foi pela paz, notadamente para que a guerra civil, mantida por grupos guerrilheiros e em curso na Jamaica tivesse fim. O único em transe na foto é o próprio Bob Marley. Os adversários mantém apenas, a contragosto, a aparência de que seja possível estarem unidos.

Há um elemento teológico, de cunho religioso e espiritual subjacente à atividade em torno da paz. Este elemento mantém presença no hinduísmo de Gandhi, cristianismo de Martin Luther King, Islamismo de Malcolm X e rastafarismo para o caso de Bob Marley.

Mesmo que não se possa dizer que o processo de se estabelecer uma cultura de paz dependa da religião, é certo que fortes manifestações em torno da pacificação têm a ver com opções de percepção da realidade fundadas em determinado viés teologicamente vinculado. A percepção da unidade dos seres humanos, além das aparências e distinções pessoais é, no fundo, uma derivação teológica, mesmo que se postule tratar-se de um tipo de ateísmo humanista.

Em qualquer hipótese, a assunção de uma cultura de paz, por ser derivada, depende de formatar-se $a$ posteriori. A cultura da paz não é algo que se encontra posto de antemão; é algo que se compreende somente no ultermão, ${ }^{3}$ pela força da caminhada.

Do visto, fica claro que o conceito de cultura de paz enseja discussão bastante ampla. De fato, a Unesco, ao tratar da disposição deste tema o coloca dentro do conceito geral de desenvolvimento sustentável. O fio da meada que liga a cultura de paz ao desenvolvimento sustentável é a percepção de que somente é possível articular-se o desenvolvimento sustentável como sucedâneo de fixação da cultura de paz. Da cultura de violência não é possível derivar o futuro sustentável. A insegurança da violência milita contra o futuro, razão pela qual se torna, a violência, enquanto interface cultural, empecilho crítico em relação ao futuro. A violência dizima o futuro. Dizendo a coisa de outro modo, sem a cultura de paz, não é possível perseguir um futuro humano que seja sustentável. O ser humano violento destruir-se-á a si mesmo.

A construção da cultura de paz deriva da percepção de que a violência manifesta em suas mais variadas formas impede a própria articulação do futuro. Isto porque a violência sempre se refere apenas à resolução dos problemas no presente. Para o planejamento e articulação do futuro é necessário depor armas. De armas na mão, não se estabelece diálogo, requisito fundamental para que se possa construir o caminho a ser trilhado. A violência, em última ratio, é sempre cega. ${ }^{4}$

Até aqui deve ter o leitor percebido que não tomamos posição sobre a forma em que deve dar-se a luta em torno da correção das injustiças. Entre Gandhi e Malcolm X não há como dizer-se qual seria a adequada reação em cada determinado contexto. Este problema, aliás, foi posto sob o escrutínio do teólogo luterano Dietrich Bonhoeffer.

\footnotetext{
${ }^{3}$ A palavra, infelizmente, não existe no catálogo da língua portuguesa. A culpa aí é do catálogo porque o conceito é facilmente reconhecível como antónimo de antemão, dadas as mesmas regras de construção vocabular.

${ }^{4}$ Questão aliás, debatida pelos diferentes matizes do pensamento marxista. (HARDING, 2012). Do meu ponto de vista, a violência como meio para resolver os conflitos cega que se usa de tais recursos a outras possibilidades compreensivas e hermenêuticas.
} 
Colocando-se diante de uma hipotética situação em que um motorista enlouquecido toma a decisão de matar pedestres inocentes, qual dever ser a ação do observador? Para Bonhoeffer, a ação necessária inclui tentar tirar o volante das mãos do motorista. Sinalagmática em tal consideração é que Bonhoeffer, ainda hoje considerado um dos ícones do pensamento teológico protestante, foi um dos articuladores da Operação Valkiria em qual se tinha tomado a decisão de matar Hitler (MILHOMEM, 2014). Do exemplo de Bonhoeffer é possível ver que cultura da paz, por isso mesmo, é mais amplo do que a definição de uma determinada estratégia reativa.

O caldo que parece unir a leitura de uma cultura da paz é, precisamente, o caldo cultural que nasce como resistência a todas as formas opressivas que afetam a condição humana. Neste sentido, cultura da paz se projeta como idealização de um mundo distencionado em favor de todos os seres humanos. Por isso, cultura de paz tem a ver com inclusividade, com o pensamento que se articula para fazer incluir todos. É da cultura de paz que se rechaça as discriminações e é pela cultura da paz que se faz o imperativo de aceitação de todos os diferentes. (SIMONS, 1956 [1552]). ${ }^{5}$

Paz aí, tem a ver com realização da justiça, com consolidação da igualdade de direitos para todos. Tem a ver com o conceito hebraico de Shalom porque a paz tem a ver com a justiça e sem ela, a paz não se realiza (BECK \& BROWN, 1983 [1967]). Paz não é estado de superação ou ausência de guerra e sim, é estado de superação das injustiças. Sob tal perspectiva e percepção, a paz não diz respeito a determinado momento de confecção de tratados pós-bélicos, normalmente marcados pela humilhação e derrota (MACMILLAN, 2004) e sim, diz respeito a um largo processo em que se edificam instituições que se amalgam à cultura humana de forma que a paz se produz como resultado construto a posteriori.

Paz como tal, não se refere a momentos e sim, a processos. A cultura da paz requer que, antes de haver conversa em torno da paz, que as pessoas aprendam a dançar, a olharem-se nos olhos, a ouvirem-se

\footnotetext{
${ }^{5}$ Interessante que esta carta de Menno Simons é dirigida a todos os magistrados com súplica para que estes não se deixem levar pela intolerância e assumam a piedade como forma de dirigir as suas sentenças condenatórias a quem simplesmente pensa e age diferente sem pretender trazer prejuízo a quem quer que seja. Com a evolução da estruturação política das sociedades liberais, a tolerância abandona as raízes morais e se fixa como reivindicação política conforme a proposição de Williams (Williams, 2009).
}

mutuamente. Velha sabedoria cherokee leciona que a paz se faz pelo ouvir atento em torno do cachimbo cerimonial (AVANT, 2017). Depois de muita dança é possível falar de paz. Dança, cachimbo, conversa são todos ingredientes culturais que permitem equacionar algum tipo de cultura de paz. Diz respeito a questão de se estabelecer um parâmetro suficiente da paz como construto cultural, razão pela qual, o grande desafio consiste em adotar a paz como padrão ético.

\section{CULTURA DA PAZ COMO DESAFIO ÉTICO}

\section{Paz sim; para quem?}

Quando se fala em paz, dado o contexto tensional humano, é fundamental de saber, afinal de contas, para quem é a paz? Sim, porque os diferentes grupos humanos, a partir dos seus interesses, mantém divergências em relação ao que seja paz. Paz para a lógica social burguesa significa a articulação de uma sociedade que respeite os direitos de propriedade. Paz, sob tal viés ótico, é não ser assaltado e paz é não ser morto por alguém (o outro) que se utiliza da violência. A ruptura da paz se dá, dentro da lógica burguesa, pelos outros que usam de instrumentos de violência para confrontarem o belo quadro social posto.

$\mathrm{Na}$ verdade, quando se faz a leitura das preocupações da UNESCO em torno da cultura da paz no Brasil, é possível que se interprete estarem as preocupações da ONU ligadas ao tema dos homicídios. Os responsáveis por tais homicídios seriam, considerando a hermenêutica burguesa, os outros, ladrões, marginais, assassinos. Estes elementos comporiam o quadro da violência que permeia o imaginário social.

Este quadro que se molda no imaginário social é reforçado por programas televisivos que recalcam a ideia de que o problema da violência decorre da marginalidade. A solução simplista para o problema posto se daria pela construção de mais penitenciárias, maior armamento das forças de seguridade pública, maior rigor e intolerância penal.

Entre outros fatores, é este recalque um dos motivos ensejadores da eleição de Jair Bolsonaro à presidência do Brasil. O caso diz respeito a um programa burguês de autolegitimação por meio do sucessivo 
reinforcement do próprio ideário. ${ }^{6}$ Constrói-se assim, a hegemonia ${ }^{7}$ das armas ideológicas que mantém o sistema em funcionamento (HINKELAMMERT, As Armas Ideológicas da Morte, 1983). A percepção de que a violência jaz na própria estrutura do capitalismo leva à formatação contrapositiva do mercado, aqui entendido como sinônimo de capitalismo, em relação aos direitos humanos (HINKELAMMERT, Mercado Versus Direitos Humanos, 2013), ${ }^{8}$ incluso aí, a conformação de uma cultura de paz.

Então, ao se considerar a palavra violência, a mesma pode ser considerada como atividade exercida por marginais sociais de modo simplista e que, na mesma lógica simplista, bastaria, para solvência do problema, aumento da força repressiva dos agentes de seguridade pública. Este modo simplista ignora que a violência jaz encalacrada no próprio sistema capitalista.

É pela violência da ideologia sistêmica que é silenciada e abafada a luta de classes. Como consequência deste silêncio ideológico deriva a noção que se entende impoluta de que a doutrinação é algo afeto exclusivamente às doutrinas de esquerda. Ingênua ou de má-fé se sustenta a posição de que a direita política não tem programa doutrinário. Os ofendículos que se sobrepõem aos muros dos condomínios horizontais manifestam em desnudo a violência que separa uns e outros. Trata-se, então, da violência que se institucionaliza no cotidiano e, por conta de tal institucionalização, os homicídios acabam por evidenciar manifestações e reações ao que está socialmente pressurizado. ${ }^{9}$

${ }^{6} \mathrm{O}$ sentido do inglês reinforcement é de difícil tradução. O significado da palavra depende muito do contexto de uso. Aponta para a provisão de excesso para determinada tarefa. Por exemplo, soldados extras para o cumprimento de determinada missão são reinforcements. Mas, também é possível pensar em reinforcement como reforço, consolidação. No caso da engenharia civil, a palavra designa a armação de concreto e, na psicologia, o recalque. Uso a palavra em inglês porque penso ser importante preservar a ideia do movimento de forçar novamente, reforçar, de botar pressão para que a coisa aconteça. O contexto vai definir a melhor tradução para cada ocorrência da palavra.

${ }^{7} \mathrm{O}$ conceito de hegemonia, quase que automaticamente, remete o pensamento a Gramsci e denota construção conceitual afeta à tradição marxista que vai sendo ampliado, tanto por novas publicações da obra gramsciana (SCHLESENER, 2016), quanto por processos de reinterpretação a partir de outras contribuições teóricas (ALVES, 2010).

${ }^{8} \mathrm{O}$ título da edição espanhola que serviu para a edição em português é $L o$ indispensable es inútil. Hacia uma espiritualidad de la liberación. O que é indispensável é que se configura a partir da ótica dos direitos humanos. Mas, argumenta Hinkelammert nas entrevista que compõem a obra, que tais indispensabilidades são inúteis para o mercado que se constrói a partir de outra lógica.

${ }^{9}$ Esclareço que estou bem ciente de que nem toda violência pode ser explicada imediata e deterministicamente a partir do contexto de exclusão social. Há casos transcendentes, de distúrbios psiquiátricos incompreensíveis que não
Sem clara percepção de que se encontra a sociedade doente, em verdadeiro surto de esquizofrenia, não há como falar-se apropriadamente em conformação de qualquer cultura de paz porque, em tal caso, se providenciaria tratamento da doença pela imobilização ou sedação do paciente. A violência jaz na sociedade que a afasta de si mesma pela cosmética da ideologização conceitual do que seja paz. Paz, sob tal ótica ideologizada e cosmética, corresponde à ausência da violência marginal. Esta ausência da violência marginal, por sua vez, se produziria pelo concomitante e proporcional aumento da repressão. É apenas sob fundamento da inépcia perceptiva ideológica quanto à sistematização da violência estrutural que não se compreende a filósofa Márcia Tiburi explicitar que reconhece certa lógica no assalto. ${ }^{10}$

\section{Reconstrução ética da paz}

A clara percepção dos instrumentos que mantém a estruturação da violência na sociedade reclama que o tema seja rediscutido sob o ponto de vista da ética. De fato, não basta, para considerar a paz, torna-la mero substrato temático da lógica burguesa. A paz não é a ausência da violência porque esta pode estar determinada ideologicamente sob determinado padrão de moralidade (tema que se compreende adiante, a partir da Figura 2). É preciso compreender que a ética se faz pela indagação dos princípios norteadores do comportamento humano.

Então, construir culturalmente a paz significa estabelecer o prumo ético da paz. Sem que se discuta, sob o prisma da filosofia ética, as causalidades da violência estrutural, não há como construir-se qualquer cultura da paz. Por essa razão, pontuamos supra que a cultura da paz é um construto a posteriori. Reclama, $a$ priori, a conformação do diálogo que toma por ponto de partida a adoção da ética como resultado do pensamento crítico em relação à própria posição analítica.

\footnotetext{
podem se restringir à monocausalidade das chagas sociais. Todavia, mesmo que não seja possível pensar-se em polaridade analítica dual restrita para este caso, em qualquer hipótese, tratar as causas das chagas sociais estabelece ponto prioritário de atuação de qualquer reflexão consistente sobre a cultura de paz. ${ }^{10}$ Como ela foi candidata ao governo do Estado de São Paulo, há diversos vídeos que registram o discurso em que ela procura explicitar a lógica que deriva da prática do assalto (Tiburi, 2018). Como se pode imaginar, o vídeo se replica ad nauseam porque a incompreensão serve para o reinforcement da própria incompreensão.
} 
Poderia ser o caso de se articular tal pensamento crítico conforme a densa sugestão de Rawls de que a justiça se poderia mensurar pela adoção da posição do outro (RAWLS, 2012 [1971])? Dusell entende que o posicionamento de Rawls é, na verdade, desvio do problema (DUSSEL, 2012) porque, de fato, não é possível assumir a posição do outro. Em Rawls, conforme o argumento de Dusell (DUSSEL, 2012, pp. 178-182), trata-se de uma lógica que prima pelo formalismo; é, no fundo, um idealismo. A questão, para Dussel é que a ética tem de construir-se a partir e sob os fundamentos da exclusão.

São os excluídos, os marginais, os que são postos para fora de nosso belo quadro social global, os que devem fazer parte do refletir ético. Isto configura o a priori para qualquer construção ética sustentável de qualquer cultura de paz. Não é possível construir uma cultura de paz a partir do senso comum, mal que afeta notadamente juristas (STRECK, 2017, pp. 269-271) que tem o dever de libertarem-se do maquinismo das verdades prontas, isto porque, o senso comum proporciona a 'simplificação'do mundo jurídico, através do qual o jurista se 'socializa' e interpreta o Direito. (STRECK, 2017, p. 271).

Daí que, pelo lado inverso, corresponde à conformação de uma cultura da violência o expurgo da filosofia da formação humana. É da conformação da violência social o desprezo pela reflexão ética, tudo para que se construa uma pedagogia do opressor em detrimento de uma pedagogia do oprimido (FREIRE, 1994 [1970]). A educação bancária não diz respeito apenas a um método de ensino; diz muito mais, a respeito de uma sistematização da mecânica opressiva. É aquele que sabe contra o que não sabe que vai dizer como as coisas têm de ser. Sobre este ponto, interessante observar que a cultura da violência também se articula sob diferentes pretensões a partir do regresso ao ideário liberal, ponto a partir do qual se faz crítica à propositura libertária dos excluídos (GIULLIANO, 2017).

O que perpassa tais críticas, no fundo, é a ideia de que a exclusão não é endógena ao sistema capitalista. Os oprimidos são, eles próprios, culpados de estarem em condição de marginalidade. Trata-se da configuração capitalista do cinismo como forma propositiva de convívio social.

$\mathrm{O}$ que se quer na perpetração da cultura de violência? Quer-se manter as aparências sociais pelo rechaço a qualquer lógica inclusiva. Os oprimidos que se mantenham em seus devidos lugares, que se mantenham excluídos, que se mantenham apartados para que não cheguem eles à consciência de sua própria situação. Consciência aí interpretada como doutrinação.

Rigoberta Menchú, por exemplo, prêmio Nobel da Paz de 1992 seria um destes casos explícitos de doutrinação da qual se deveria manter afastada a sociedade da cosmética capitalista. A questão, como posta por Rigoberta é que a consciência se faz da reflexão da própria condição vital (MENCHÚ, 1983). Daí que, por doutrinação se pretende expurgar da consciência o próprio pensamento. Na sociedade violenta, persiste o vazio de pensamento e o mal se torna banal como ponderou Hanna Arendt a partir das observações do julgamento de Adolf Eichmann (ANDRADE, 2010).

\section{CULTURA DA PAZ E LINGUAGEM}

\section{Eu e tu}

Afastar o pensamento para evitar a doutrinação. Em síntese, o que a sociedade violenta propõe é a legitimação da lógica da exclusão para que seja possível construir um sistema de aparência e cosmética pacífica. É precisamente neste ponto que se cruzam as lógicas do capitalismo com as lógicas do fascismo. O fascismo, por não estabelecer cultura dialógica, divisa, nas contradições sociais, elementos que devem ser expurgados. O ponto de observação fascista é o capitalismo desde sua coesão e retórica burguesa. Diferentemente do capitalismo liberal, que joga dentro de determinadas regras políticas, o fascismo se apodera do discurso supressivo das contradições.

É o fascismo como doutrina consolidada que se propõe a resolver as contradições da democracia, a quem considera sistema obsoleto (POLANYI, 2012 [1935]). A obsolescência da democracia se dá, precisamente, em sua incapacidade de dissolver as contradições da sociedade e por isso, o fascismo se dá pelo brutal reinforcement do sistema capitalista. Trata-se da máxima do novo liberalismo de que mais capitalismo é o modo de se resolver os problemas do capitalismo. A triste verdade, é que, no horizonte à vista, não há recuperação econômica (ROBERTS, 2013), isto dito por quem assumiu no passado, a teoria econômica do liberalismo. 
Contra tal lógica de consolidação e reforço do capitalismo e do mercado como endógenos excludentes se posta a ética que faz aposta na educação como fundamento da construção de qualquer cultura, especialmente de uma cultura de paz. Educação significa aqui o processo de conformação da consciência de si mesmo e do outro. Esta consciência de si mesmo permite a proposição de um novo patamar em que o eu percebe no outro, o interlocutor do diálogo. Cultura e diálogo são faces de uma mesma moeda. É no encontro do eu com o tu que se personifica a construção dialógica (BUBER, 1977 [1923]).

Muito bem, e o que tem a ver diálogo e cultura de paz? Tudo a ver! Cultura de paz não é a ausência de violência e sim, a superação da empedernida violência pelo diálogo como modus vivendi. Não por qualquer diálogo e sim, pelo diálogo compromissado em que se busca a compreensão, não apenas do lugar do outro como, de fato, a compreensão do outro. A cultura da paz se manifesta como exercício compreensivo. É, portanto, um construto hermenêutico dialógico a posteriori. Somente pode ser a posteriori porque decorre do diálogo e este, a sua vez, deriva do processo pedagógico. Estas verdades são importantes descobertas dos processos mediativos e de conciliação humanista. Os conflitos são enfrentados dialogicamente para que se chegue à conciliação humanista (SOUSA, 2017).

Cultura da paz, por estes motivos, é algo de construção difícil. Existe, de modo fácil, na cosmética do próprio capitalismo de suposto livre mercado que reclama, por sua completa loucura, a sua superação por algo diferente (UBEL, 2014). Mas aí, nesta loucura do livre mercado, trata-se de processos de invisibilização planejada das contradições sociais. ${ }^{11}$ Não é preciso doutrinar as pessoas sobre o sistema capitalista porque isto se faz dentro do próprio sistema; a loucura é endógena. Daí também, a propalada noção de naturalismo capitalista se manifesta como ilusão de ótica e de perspectiva.

Dentro de tal naturalismo, é natural, por exemplo, que existam trabalhadores e capitalistas e que, apenas aos últimos seja reservada a propriedade do capital. Também se entende natural e até necessário que os proprietários do capital financeiro cobrem rendas sobre os empréstimos de capital. A usura proibida

\footnotetext{
${ }^{11}$ Tome-se o exemplo da homossexualidade a ser admitida apenas sob as condições da invisibilidade (SANELLO, 2011). Esta invisibilidade fica evidente também na Rússia (KONDAKOV, 2010).
}

do passado se torna a impostergável necessidade do presente. Este naturalismo se confunde com o senso comum e este, como já mencionado, não tem legitimidade para a construção de qualquer cultura de paz. Por isso se pode falar da violência do capitalismo financeiro (MARAZZI, 2011). Não tem legitimidade por desprezar o pensamento, por deixar de articular-se eticamente e por evitar o diálogo que, necessariamente, traz à tona a conflitividade social.

A paz retratada pela refeição familiar burguesa do século XIX ou mesmo pelos bailes das cortes reais não serve de parâmetro para o estabelecimento da cultura de paz. Por que não? Porque, da mesa de refeição estão exclusos os outros e dos bailes não participa a ralé. A cultura de paz não pode ser aquela que aparece no quadro da família brasileira, de 1839, de Jean Baptiste Debret.

Figura 2: Quadro da Família Brasileira no Rio de Janeiro, 1839 - Debret

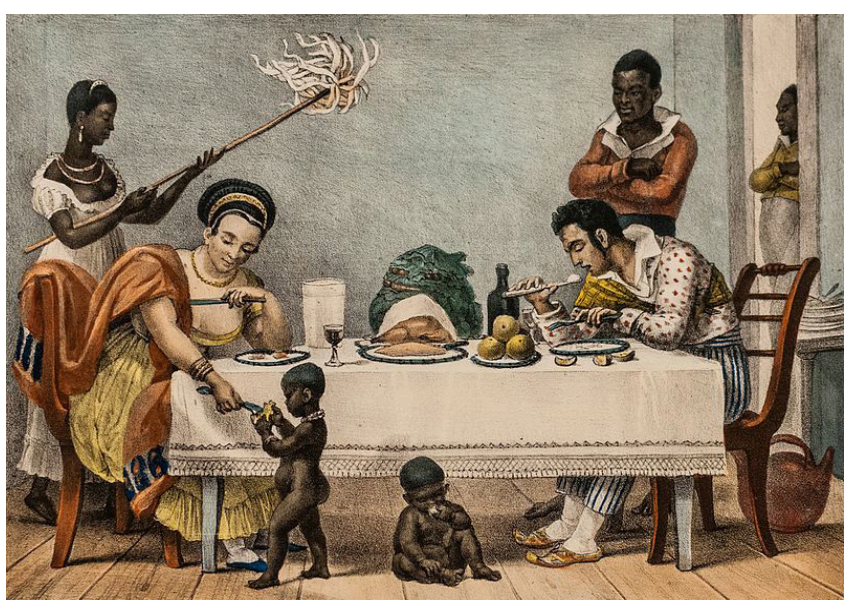

FONTE: https://www.historiadasartes.com/prazer-emconhecer/jean-baptiste-debret/ [Internet]

O quadro de Debret foca a família brasileira a partir do paradigma da raça branca. Os pretos não fazem parte da família. Compõem o quadro sem que nele tenham protagonismo. Este somente haveria de ocorrer pela consciência e pelo estabelecimento de uma cultura do diálogo. O quadro retrata, além da refeição, a cultura do silêncio à qual se refere Freire (FREIRE, 1994 [1970]). É pela ausência de diálogo que se constrói a cultura da violência. É esta cultura da violência que bem está retratada no quadro de Debret. Mas aí, não se dá o caso de doutrinar alguém para que perceba a violência aí pintada. Trata-se de perceber o processo de conformação da consciência, de saber 
perceber e distinguir luz e sombras, realidade e fantasia, o real e o imaginário (PLATÃO, 2000 [300]). Trata-se aí, no caso da pintura de Debret, de uma paz de ultraje, um tipo de paz vilipendiosa, que se produz sob fórceps. É este tipo de paz natural que se pretende impor sobre todos que jazem sob o guarda-chuvas da hegemonia do capital.

\section{Linguagem como mecanismo construtivista}

A cultura de paz se fundamenta e se constrói desde o diálogo. Este, compreensivo, estabelecedor de compreensão das próprias razões de ser e das razões do outro. A cultura de paz se propõe como superação das manifestas expressões da violência institucionalizada. Daí que se requer, para o estabelecimento da cultura de paz, o desdobrar dos mecanismos da linguagem dialógica. Trata-se aí, de estabelecer sério esforço de superação das incompreensões pela construção de pontes de diálogo. Isto porque, a violência não apenas se manifesta no punho cerrado daquele que agride outro como também e de modo especial, na ausência do verbo. A violência se faz pelo silêncio. Silêncio a que se obriga o outro. É o constrangimento ao silencio que manifesta as relações de dominação e de poder. Mandar calar a boca significa mais do que a supressão do verbo; é o desejo de que o outro desista de resistir. É por isso que, no estupro, a mulher tem a boca tapada.

Cultura da paz se faz não por processo cosmético; se faz pelo esforço dialógico. Paz não se constrói pela pintura nova (São Mateus, 23,27); se faz pelo inclusivo processo educacional em que a pessoa chega à consciência de si mesmo e do outro. A restauração do outro face aos conflitos sociais, portanto, se faz por políticas públicas; é disso que estamos falando. Cultura de paz corresponde a uma instituição que deve ser estruturada politicamente.

Infelizmente, em terras tupiniquins o trabalho de construção de uma cultura de paz depende de muito trabalho. Isto fica perceptível a partir da analítica do contexto da linguagem tensionada no campo da política. É nas redes sociais e nas manifestações políticas que fica manifesto o universo da linguagem destrutivista, aquela que se lança ao léu, sem qualquer esforço interpretativo. Tal linguagem, por sua lacuna hermenêutica, deve recorrer aos impropérios para fazer-se valer. Não vem ao caso desfilar os impropérios que se lançaram e se continuam a lançar nas redes sociais porque ali abriram-se as porteiras para a manifestação do mais ignóbil e tosco ódio ao outro.

Figura 3: Bonecos nas manifestações favoráveis ao impedimento de Dilma

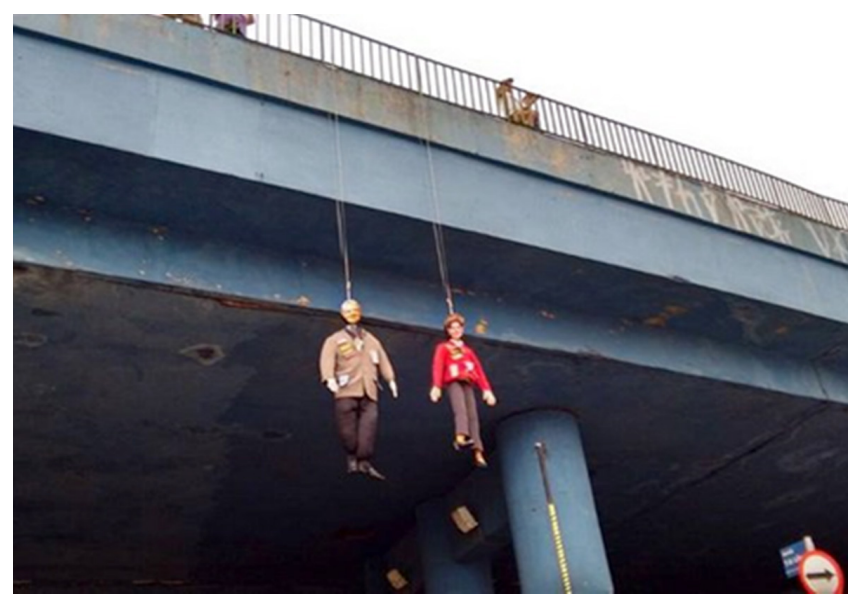

FONTE: https://blogdomariomagalhaes.blogosfera.uol.com. br/2016/04/11/rastros-de-odio-1/ [Internet]

Aqui, mesmo que o autor do presente artigo tenha posicionamento político bem definido, não vem ao caso de, neste artigo, discutir-se a política em si mesma. O que está em foco é a viabilidade de construção de uma sólida cultura de paz e por aí, passa o universo da linguagem dialógico. Do atento olhar para o que comunica a Figura 3 é preciso haver séria indagação sobre o universo da linguagem como expressão da violência. A violência não se dá, primeiro, pelo porte de arma; se dá, primeiro, pelo uso verbal e não verbal da linguagem.

Construir cultura de paz requer a desconstrução da mítica discursiva em torno da violência. Tal propositura é necessária porque democracia e cultura de paz perfazem unidade de sentido. Não é possível construir democracia se são violentas as águas do rio contra o demos que lhe dá nome. Ao se pendurarem bonecos sob a ponte (Figura 3), deixam estes de representar pessoas e passam a ser estigmas. É a estigmatização da humanidade que conduz à desfiguração do outro. Se no outro não vejo meu semelhante, tampouco vejo razões para que seja respeitado. É da radicalização da cultura da exclusão que se legitima a política dos extermínios.

Não é possível, neste artigo que reflete sobre a cultura da paz, deixar de lado manifestação de profundo pesar e desconforto com os rumos que foram 
eleitoralmente definidos para o país. Isto porque, independentemente de qualquer prejuízo sobre o governo a ser empossado em 2019, faz parte da discursiva do futuro presidente e, por decorrência, de muitos eleitores seus, a defesa da mais tosca linguagem lógica de exclusão. Sob as marcas da inconsciência, os oprimidos votaram nos que lhe são adversos. No fundo, a constatação de tal inconsciência coloca em pauta a própria legitimidade do processo eleitoral como forma de garantir-se que o poder pertença ao povo e que em seu nome há de ser exercido.

Cultura da paz tem de ser construída e tal construção depende da consciência de si e da capacidade dialógica. Cultura da paz tem de ser construída sob os fundamentos da democracia porque, fora de tal consideração, haveria manutenção da lógica de exclusão. Cultura da paz tem de ser construída no mesmo processo construtivo da democracia porque, paz, além da lógica do cala boca (lógica do silêncio), é aquela em que as pessoas podem falar e apresentar, na mesa do diálogo, os conflitos e as ambiguidades inerentes à condição humana (MEDEIROS \& NORONHA, 2015). ${ }^{12}$

\section{CULTURA DA PAZ E CONTEXTO DE VIOLÊNCIA}

\section{Violência e cotidiano}

O cotidiano é violento e isto se percebe além das aparências. Quem sabe por isso, juntar as mãos no concerto de Bob Marley (veja Figura 1) não tenha produzido resultado prático. É uma imagem que carrega força simbólica de como se poderia construir a cultura de paz. Da foto se vê que os adversários juntam esforços em aparência. São constrangidos para tal e constrangidos sinalizam existir uma aparente aceitação mútua. Da imagem vem a certeza de que estabelecer cultura da paz transcende as questões cosméticas. É preciso saber filosofar. É preciso mergulhar intensamente na aventura compreensiva e isto se faz como processo e como pedagogia.

\footnotetext{
${ }^{12}$ Podem ser levantadas críticas contra a postura de Habermas por seu abandono do marxismo crítico estabelecido pela Escola de Frankfurt. Apesar das críticas, a propositura de uma práxis da ação comunicativa acaba por aproximar Habermas de Freire. Esta leitura da pedagogia comunicativa como esforço vivencial para a criação de uma cultura humana pacífica não pode ser deixada de lado.
}

A farda policial que porta a autoridade não elide a violência do cotidiano. É a presença da farda, pelo contrário, que faz permanente lembrete de que a violência está enredada no cotidiano. O cotidiano é violento e a percepção desta violência arraigada não depende de doutrinação; depende da consciência. Olhar para as figuras que trouxe para este artigo podem não escancarar a violência. Mas, ela está lá. É preciso ter olhos abertos e consciência receptiva para ver.

Assisti, em 2014, o filme Em um Mundo Melhor (Jensen, 2010), que ganhou o Oscar de melhor filme estrangeiro de 2011. O que tem de especial neste filme é a abordagem da conformação da cultura de paz. Trata-se de uma produção conjunta da Dinamarca e Suécia, países que mantém, não apenas altos índices de desenvolvimento humano como, também, forte indicativo de felicidade. De fato, a Dinamarca é tipo pelo índice global da paz, um dos países mais pacíficos do mundo ${ }^{13}$ e um dos mais felizes também. Pois bem, assistir "Em um Mundo Melhor" me fez perceber (tomar consciência) de quão distante está o Brasil de construir uma verdadeira cultura de paz. Isto significa reconhecer que o processo educacional brasileiro não prepara as pessoas para a paz. Trata-se de manutenção nos bancos escolares de uma pedagogia das aparências, porque sabem os educandos que a vida escolar é apenas um faz-de-conta em relação ao cotidiano. $\mathrm{Na}$ vida real, fora das sombras, ${ }^{14}$ a sociedade manterá a violência como forma de resolução dos conflitos.

A consciência em relação à cosmética da paz é importante para o caso brasileiro porque o índice global paz no quesito intensidade dos conflitos internos avalia que o Brasil esteja no grau mais elevado da pacificação. Isto somente é possível na medida em que os conflitos internos brasileiros são mascarados, na medida em que eles não emergem violentamente.

A falta de emergência marca a construção do homem cordial (HOLANDA, 1995 [1936]) e denota a mentalidade elitista brasileira (SOUZA, A Elite do Atraso, 2017). A cultura de paz desta elite se faz

\footnotetext{
${ }^{13}$ Informações disponíveis em http://visionofhumanity.org/indexes/global-peace-index/ [internet], acesso em 08 de novembro de 2018.

${ }^{14} \mathrm{E}$ aqui, eu mesmo, algo assustado, confesso e me impressiono de colocar a escola no lado das sombras. Este mundo sombrio fica muito mais tenebroso ao se pensar nas propostas que vão sendo articuladas pela Escola sem Partido. Tudo isto porque subjaz a tal articulação a ideia de que apenas a esquerda produz doutrinação. As coisas como são se consideram dadas. É dado o capitalismo e dada a situação de violência estrutural que não podem ser questionados. É este o rescaldo da enorme bobagem que é a escola sem partidos.
} 
apenas pela admissão de subcidadanias, estas marcadas pelo silêncio e incapacidade reativa (SOUZA, Subcidadania Brasileira; Para Entender o País além do Jeitinho Brasileiro, 2018).

Chegado a este ponto, penso não ser possível dizer que estabelecimento da cultura da paz deva seguir uma determinada linha de reação. Particularmente, por questões teológicas, entendo que a postura assumida por Gandhi e Martin Luther King é a melhor forma de se opor a um sistema contextual de violência institucionalizada. Mas, de igual modo, não posso dizer que a posição assumida por Malcolm X ou mesmo pelos panteras negras não possa ser defendida quando se fala em cultura da paz. As reações contra a opressão são parte do movimento antecedente ao estabelecimento da cultura de paz. São parte antecedente porque a cultura de paz requer parceiros iguais de diálogo; enquanto existir opressão, a relação não mais se dá como dialógica e sim, como relação EU versus ISSO (BUBER, 1977 [1923]).

$\mathrm{O}$ fato é que as reações à violência institucionalizada são movimentos necessários. É preciso reagir à violência. Esta reação faz parte da construção dialógica em que o oprimido levanta a sua voz para dizer que o flagelo que lhe é imposto dói. Desobediência civil faz parte da condição humana como atravessar o necessário período da adolescência para que o mundo adulto seja possível. A contestação é necessária para que a violência institucionalizada ceda espaço para uma nova cultura que a substitua. $\mathrm{O}$ que pode estar em divergência é a forma de contestação.

Neste ponto abre-se a inflexão necessária para compreender-se que há diferença reativa entre a luta do opressor contra o oprimido e a luta do opressor para manter o status quo. O que está em questão aí, é a legitimidade da luta. Esta legitimidade descansa suas raízes nos direitos humanos. O ser humano tem direitos que não lhe podem ser suprimidos. Entre estes se encontra o dever de resistência que decorre da defesa dos direitos humanos. Torno-me humano, não apenas por direitos que me são concedidos, e sim e notadamente, pelo dever que tenho de lutar para que os reconhecidos direitos de todos sejam garantidos. Ao lutar pelos meus direitos, luto pelos direitos de todos.

Resistir ao mal faz parte do recheio de tudo que possa ser compreendido como cultura de paz. Cultura de paz, então, não é a forçar que a sociedade se torne apática. Pelo contrário, cultura de paz significa que a sociedade conscientemente se direciona para resistir ao mal. As formas de resistência não definem a cultura da paz e sim, o modo pelo qual se processa o construto dialógico como cerne da consciência humana.

\section{Cultura e alvo a alcançar}

A meta ou alvo a alcançar não é a apatia, a ausência de sensibilidade ou o mórbido desinteresse pelo outro. Pelo contrário, a meta da cultura da paz é desenvolver o ser humano em direção à verdadeira vivacidade do comprometimento de superação da indolência que mascara a intolerância para com quem pensa diferente. A paz se faz como meta de permeio cultural. Paz, então, tem de ser declamada em prosa e verso. Tem de ser vivida no cotidiano, tem de gerar diálogo e resistir à censura. Paz tem a ver com o direito inalienável à liberdade de pensamento e paz, por tudo isto, não se confunde com a conveniência da imposição de modelos opressores. Paz tem a ver com resistir. Somente tem sentido falar da paz quando as suas asas podem estar abertas para alçar vôo. Sinal da liberdade são as asas abertas; fechadas, não alçam o espaço aberto.

Paz tem a ver com a emergência de uma cultura que respire a paz. Distingue-se aí, da paz arranjada, que se coloca como imposição sobre outros que devem submeter-se ao poder do mais forte. Não há paz quando a mulher está obrigada a suportar o marido que lhe impõe a censura; não há paz quando os assuntos se resolvem no porrete. Não há paz quando o sistema vive e transborda a exploração capitalista dos semelhantes. Paz somente se constrói como resultado do mundo adulto e isto como consistente movimento cultural. A cultura da paz aí, deve interpretar-se ao revés. A paz somente se atinge quando a cultura digere a paz e a cultura à paz se submete porque o alimento se integra e perfaz o ser daquela que se alimenta. Alimentar-se da paz é a única maneira de se viver de, em e pela paz.

$\mathrm{O}$ direito de resistência é a marca que marca diferentes movimentos sociais. O MST, por exemplo, adota estratégias de resistência. Resistir é preciso porque o direito humano à propriedade (art. $17 \mathrm{da}$ Declaração Universal dos Direitos Humanos) somente faz sentido se esta puder ser para todos. Todos os seres humanos devem compartilhar a terra de todos. Sem esta consciência desperta, a terra será de uns contra outros. O mesmo se aplica a todas as questões sociais 
que se fazem pela luta e resistência. Não é possível pensar-se em cultura da paz para os viventes que resolvem suas vidas embaixo das pontes como também não é possível pensar que a humanidade deva dividir-se entre proprietários e despossuídos; entre homens e mulheres; entre credores e devedores (GRAEBER, 2011). Sejamos muito francos; a cultura da paz tem de confrontar-se com o triunfo do dinheiro porque é o dinheiro que move o mundo. (FERGUSON, 2010).

\section{CONCLUSÃO}

Cultura da paz é uma aposta radical. Demanda de todos os seres humanos que saibam olhar o próximo e não apenas seu próprio umbigo. Que saibam valorar as pessoas fora das cantilenas utilitaristas de que o valor do outro é uma função de quanto o outro é útil para mim. A cultura da paz é reticente à lógica da prostituição geral da humanidade. Cultura da paz se faz por reclamo de um mundo novo e diferente. Demanda, tal cultura, que se aprenda a importância do diálogo. Demanda que as pessoas se tornem adultas e que deixem de lado mesquinharias. Que compreendam não decorrerem os males da terra da doutrinação e sim, da tomada de consciência. Cultura da paz se faz apenas na medida em que a paz se embrenhe na cultura. Isto quer dizer, no fundo mesmo, que a cultura da paz tem de respirar em muitas medidas, os ares do socialismo (CASAS, 2012). ${ }^{15}$

Não importa como a cultura da paz seja articulada no presente; para o futuro ou como meta programática, a cultura da paz tem a ver com o integral respeito às pessoas e ao trato das questões sociais. Mesmo que o bem estar não seja classificado como integrante da lógica teórica do socialismo, não se pode negar que os países escandinavos aprenderam que o caminho da cultura de paz precisa ser trilhado. Tem de ser trilhado porque, em ultima ratio, não há alternativa possível. A violência e a cultura da violência contém

\footnotetext{
${ }^{15}$ CASAS em verdade, discute a situação de se construir uma economia que se direcione para a superação da pobreza. Mas, o faz sem fixar-se no simplório receituário do liberalismo de que basta que cresça a economia para que, automaticamente os benefícios do crescimento se repartam entre a sociedade. Não é assim porque é preciso discutir (dialogar) sobre o que deve ser feito. Por isso, diz ele "creo em la necessidade de pensar y discutir acerca de los criterios básicos para organizar una economia que tenga objetivos explícitos em estos tempos, en los que se habla em América Latina del "Socialismo del siglo xxi". (...) La idea es estar preparados, tener critérios para encarar la organización económica cuando se produzca la oportunidad, en lugar de improvisar todo, con los riesgos de fracaso que eso implica." (CASAS, 2012, p. 364)
}

em si mesmas, o germe da sua destruição. Tal qual parasitas, ao se destruírem, destroem também os seus hospedeiros, sem qualquer remorso.

\section{REFERÊNCIAS}

ALVES, A. R. C. O Conceito de Hegemonia: De Gramsci a Laclau e Mouffe. Lua Nova, Issue 80, 2010, p. 71-96.

ANDRADE, M. A Banalidade do Mal e as Possibilidades da Educação Moral: Contribuições Arendtianas. Revista Brasileira de Educação, Volume 15, 2010, p. 109-199.

AVANT, J. T. Talking Stick and Feather: Indigenous Tools Hold Sacred Power of Free Speech, 2017. Disponível em:

https://newsmaven.io/indiancountrytoday/archive/talkingstick-and-feather-indigenous-tools-hold-sacred-power-offree-speech-HIxdWMdV60CeaMvIVwfqnA/ Acesso em 07 novembro 2018.

BAMAN, K. C., Mahatma Gandhi and Various Issues of the Indian National Congress: A Brief Study. Imperial Journal of Interdisciplinary Research (IJIR), janeiro, 2016, p. 178-186.

BECK, H. \& BROWN, C. Paz. Em: Novo Dicionário Internacional de Teologia do Novo Testamento. São Paulo: Vida Nova, 1983, p. 474-480.

BUBER, M. Eu e Tu. São Paulo: Moraes [1923]. 1977.

CASAS, F. D. Hacia una Economía sin Pobreza. Córdoba: Eduvim. 2012.

COSTA, M. M. M. \& COLET, C. P. A Aplicabilidade dos Mecanismos Restaurativos como Forma de Participação Popular e Efetivação da Cidadania; A Solidificação das Redes de Cooperação e do Capital Social. In: Justiça Restaurativa e Mediação; Políticas Públicas no Tratamento dos Conflitos Sociais. Ijuí: Unijuí, pp. 73-102. 2011.

DUSSEL, E. Ética da Libertação, na Idade da Globalização e da Exclusão. 4ª ed. Petrópolis: Vozes. 2012.

Em um mundo melhor. Direção: Susanne Bier. Dinamarca: Universal, 2010. 1 DVD, son., cor.

FERGUSON, N. El Triunfo del Dinero; Cómo las Finanzas Mueven el Mundo. Buenos Aires: Debate. 2010.

FISHER, L. Gandhi. São Paulo: Círculo do Livro, 1983.

FREIRE, P. Pedagogia do Oprimido. $17^{\mathrm{a}}$ ed. São Paulo: Paz e Terra, 1994.

GELDERLOOS, P. Como a não-violência protege o Estado. São Paulo: Subta, 2007.

GIUlliano, T. Desconstruindo Paulo Freire. Porto Alegre: História Expressa, 2017.

GRAEBER, D. Debt; The First 5,000 years. London: Melville House, 2011. 
HARDING, N. Violência. Em: Dicionário do Pensamento Marxista. $2^{\mathrm{a}}$ ed. Rio de Janeiro: Zahar, 2012, p. 596-597.

HENRIQUE, G., 2018. Lula Merece o Prêmio Nobel da Paz, São Paulo: s.n, 2018.

HINKELAMMERT, F. As Armas Ideológicas da Morte. São Paulo: Paulinas, 1983.

HINKELAMMERT, F. Mercado Versus Direitos Humanos. São Paulo: Paulus, 2013.

HOLANDA, S. B. Raizes do Brasil. São Paulo: Companhia das Letras, 1995.

KONDAKOV, A. The Invisible People: Gay and Lesbian Subjects of Discourses in Russia. Saarbrücken: VDM Verlag Dr. Müller, 2010.

MaCMiLlan, M. Paz em Paris 1919; A Conferência de Paris e seu Mister de Encerrar a Grande Guerra. Rio de Janeiro: Nova Fronteira, 2004.

MARAZZI, C. The Violence of Financial Capitalism. Los Angeles: Semiotext(e), 2011.

MARCONDES, G. S., SOUZA; H. A. Q; GOUVÊA, Josélia Henriques Pio \& CARVALHO, Matheus Landau. Mahatma Gandhi e seu diálogo inter-religioso co o cristianismo na busca pela verdade. Sacrilegens - Revista dos Alunos do Programa de Pós-Graduação em Ciência da Religião - UFJF, v. 9, 2012, p. 105-123.

MEDEIROS, A. M. \& NORONHA, N. M. Ação Comunicativa e Ação Dialógica: Diàlogos entre Jürgen Habermas e Paulo Freire no âmbito da 'Esfera Pública'. II Congresso Nacional da Educação, 2015, p. 12.

MENCHÚ, R. Me llamo Rigoberta Menchú y así me nació la conciencia. Cuba: Casa de las Américas, 1983.

MIGUEL, S. N. Gandhi e a Verdade: Reflexões entre Autobiografia e História. Aedos, v. 3, janeiro-junho, 2011, p. $87-110$.

MILHOMEM, F. C. H. Tensões Ético-Comunitárias em Esdras e Bonhoeffer. Fragmentos de Cultura, v. 24, jul/set, 2014, p. 413-422.

PLATÃO. A República. São Paulo: Nova Cultural, 2000.

POLANYI, K. La Esencia del Fascismo. In: Textos Escogidos. Buenos Aires: CLACSO, 2012, p. 203-230.

RAWLS, J. Teoría de la Justicia. $2^{\mathrm{a}}$ ed., $9^{\mathrm{a}}$ reimp. ed. México: Fondo de Cultura Económica [1971], 2012.

ROBERTS, P. C. The Failure of Laissez Faire Capitalism. Atlanta: Clarity Press. 2013.

SANELLO, F. Invisible People: Homosexuals in History. Seattle: Createspace Independent Publishing. 2011. 